\title{
Students perceptions on pre-clinical experience in a front-loaded nurse anesthesia program
}

\author{
Frederick Scott Imus ${ }^{* 1}$, Shari M. Burns ${ }^{1}$, Rodney Fisher ${ }^{1}$, Lee Ranalli ${ }^{2}$ \\ ${ }^{1}$ Nurse Anesthesia Program, Midwestern University, Glendale, AZ, United States \\ ${ }^{2}$ Gateway Anesthesia Associates, Gilbert, AZ, United States
}

Received: May 19, 2015

DOI: $10.5430 /$ jnep.v5n10p22
Accepted: June 3, 2015

Online Published: July 7, 2015

URL: http://dx.doi.org/10.5430/jnep.v5n10p22

\begin{abstract}
Objective: The purpose of the descriptive study was to identify the students' perceptions regarding the benefits (extent and nature) they gained by participating in a 4-hour pre-clinical experience in their nurse anesthesia program. The program initiated a modification to the existing curriculum. Based on the modification, faculty queried the students to determine if the experience supported their learning and transition to clinical education. This initial effort serves as a foundation for future research for nurse anesthesia programs as well as curriculum revision.

Methods: An online survey was used to collect data regarding the perception of the pre-clinical experience and identified changes that students made in their approach to learning. Additionally, anxiety and confidence was examined. A 21-item Likert scale style survey to explore the benefits student perceived following the 4-hour clinical training as well as any changes they made to their study practices and simulation laboratory time.

Results: Multiple benefits were identified from participating in the pre-clinical experience. Nearly all the students acknowledged that the pre-clinical experience encouraged and motivated them to learn and study the didactic curriculum. All the students agreed that the pre-clinical experience not only helped to increase their confidence but also reduced their anxiety as they transitioned to the clinical year of the nurse anesthesia program.

Conclusions: Reduced anxiety and greater confidence ease transition to clinical education. Pre-clinical experience improves preparation for clinical rotations by immersing students in the reality of the clinical environment. Students apply didactic knowledge to clinical practice and motivation to learn increases. The results of this research underscore the benefits of early clinical experience.
\end{abstract}

Key Words: Pre-clinical, Front-loaded, Academic success, Integration

\section{INTRODUCTION}

During the first nine years of Midwestern University's frontloaded Nurse Anesthesia program students dedicated the 12 months to didactic education and the second 15 months to clinical education. Didactic education provides students with a foundation in the basic sciences as well as all aspects of anesthesia equipment, basic and advanced anesthesia prin- ciples. Previously, didactic education contained no clinical experience. The program offers an elaborate high-fidelity simulation lab for students to learn and practice psychomotor skills as well as simulate anesthetic case scenarios. However, literature regarding students perception with early integration into the clinical arena as well as the students in the current study, share that students continue to display anxiety and

\footnotetext{
*Correspondence: Frederick Scott Imus; Email: fimus@ midwestern.edu; Address: Nurse Anesthesia Program, Midwestern University, Glendale, AZ 19555 N 59th Ave Glendale, United States.
} 
apprehension when transitioning to clinical education. ${ }^{[1,2]}$ This issue prompted a modification to the existing curriculum. An early clinical experience was integrated into the didactic curriculum.

In studies exploring the effects of early integration into the clinical arena, researchers determined that it was superior to have the students partake in the preclinical experience then to devote more time in the skills laboratory. Moreover, simulation in the lab improves its effectiveness when the students are integrated into a pre-clinical experience. ${ }^{[3,4]}$ Pre-clinical experience encouraged students to want to learn and study the theory about the clinical experience. ${ }^{[5]}$ This modification to the curriculum was initiated to not only decrease anxiety and apprehension but to strengthen the connection between the didactic courses and clinical practice.

While the literature is devoid of nurse anesthesia students perception of early integration into the clinical arena, there are multiple studies done outside of this subset of students which has demonstrated an array of positive effects. ${ }^{[1-6]}$ The literature supports the early integration of students into the clinical arena to relieve anxiety and to strengthen the bond between theory and practice. Students describe how the interaction with patients improved their attitude toward their didactic studies and helped them overcome anxieties and increased their confidence level associated with the clinical arena. ${ }^{[1-6]}$ With an enhanced confidence student performance was markedly improved. ${ }^{[7]}$ This immersion into the reality of the clinical environment has been shown to further improve the students' motivation for learning in their didactic course, stimulating the bond between concepts and practice. ${ }^{[8]}$ This interruption of their didactic classes is perceived as a welcome break from their studies and helps the students realize again why they choose their profession, all the while strengthening professionalism in their given practice. ${ }^{[7,8]}$ Given that early integration into the clinical arena has afforded students to develop relationships with clinical instructors as well as establish positive role models beyond their didactic faculty, it has become evident that this supports the transition from classroom to practice. Moreover when queried, clinical instructors felt that students that were integrated early into clinical practice were more equipped to handle the stresses in the clinical arena. ${ }^{[9,10]}$

There is a link between increased anxiety and decreased self-efficacy that in turn has a negative effect on student performance in the clinical setting. ${ }^{[5]}$ Students anxiety level has been one of the most predictive indicators of success; moreover anxiety-relieving interventions should be established to support success in a nurse anesthesia program. ${ }^{[8]}$ The didactic material given in a front-loaded nurse anesthesia program can be difficult to maintain due to the lack of immediate clinical application. ${ }^{[8]}$ The purpose of the students participating in a 4-hour pre-clinical experience was to enable a smoother transition into the clinical arena. Other disciplines have established that students desire pre-clinical experience. Didactic education was enhanced with the addition of a pre-clinical experience thus promoting academic success. ${ }^{[9,10]}$ Students identified the pre-clinical experience as a vital component in helping learn the theoretical concepts that again motivated the students to relate theory to practice. The purpose of this study was to identify the students' perceived benefits of a pre-clinical experience in nurse anesthesia education.

\section{METHOD}

\subsection{Design, sample and ethical considerations}

The Nurse Anesthesia Program, through its affiliation with a local anesthesia group, provided 4 hours of "hands-on" clinical experience during the didactic portion of their anesthesia educational program. Following approval by the Midwestern University Institutional Review Board (IRB), an anonymous descriptive survey was sent to 29 nurse anesthesia students following a pre-clinical experience. Students were assigned to the same clinical site for 4 hours once during the second quarter of the didactic year. Students were assigned to an operating room under the guidance of a Certified Registered Nurse Anesthetist (CRNA). Students were given the opportunity to perform anesthesia gas machine checks, draw up and give medications, perform airway management, and maintain and emerge patients from anesthesia.

\subsection{Instrumentation}

A 21-item Likert-style on-line survey explored the students' perception of the pre-clinical experience and identified any changes the students made in their approach to learning as well as their perceived anxiety and confidence as they transition to clinical education. Completing the survey was voluntary. Two additional open-ended questions were included to determine what students thought about the clinical experience. The survey addressed any benefits the student received from the 4 hours of clinical training as well as any changes made to their study habits and lab time. Since the survey was researcher generated; an expert in survey construction was consulted. The survey was examined for content validity. Also, the survey was reviewed by the faculty as well as a nurse anesthetist in clinical practice to assure items were understandable. All agreed that the survey items were valid. Given the small sample size and the first effort to examine this content, the reliability of the tools was not established. 


\subsection{Procedures}

The anonymous on-line survey was sent to 29 students who participated in the pre-clinical experience. On-line data was downloaded from Survey Monkey and securely stored in the Nurse Anesthesia Program office, Midwestern University, Glendale, Arizona. One survey reminder was sent two weeks after the initial request for participation. Data collection was completed in three weeks.

\subsection{Data analysis}

Anonymous cohort data was tabulated and analyzed using descriptive statistics (percentages). The qualitative comments were reviewed and organized by the faculty under the student's perception of the pre-clinical experience as well as identifying what hands on experience the students were able to attain.

\section{Results}

Surveys were returned by $83 \%$ (24/29) of the students. When asked if the students thought the pre-clinical experience helped reinforce the didactic curriculum, $100 \%$ strongly agreed. $96 \%$ acknowledged that the pre-clinical experience encouraged and motivated them to want to learn and study the theory linked to their experience in the pre-clinical setting. $96 \%$ of the students stated that the pre-clinical experience benefited their nurse anesthesia education. All the students agreed that pre-clinical experience not only helped to in- crease their confidence, but also reduced their anxiety going into the clinical year of the nurse anesthesia program. $83 \%$ of the sample increased the amount of time spent on reviewing the didactic curriculum (see Table 1).

While $83 \%$ of the students spent more time in the lab to improve practical skills prior to attending the pre-clinical rotation, $92 \%$ spent more time in the lab after attending the pre-clinical rotation. $100 \%$ of the students stated that the experience promoted the integration of prior knowledge and new knowledge and created an understanding of the impact of anesthesia and surgery on patients' lives. All the students agreed that the pre-clinical experience improved their understanding of future responsibilities as a nurse anesthetist and was helpful in improving their professional development. $92 \%$ of the students were able to practice airway management while $40 \%$ were able to practice checking the anesthesia gas machine. $54 \%$ of the students practiced pre-operative evaluation. Some students were able to gain experience with other aspects of anesthesia such as, placing an endotracheal tube with a glide scope and assisting with placing an inter-scalene block (see Tables 1-3).

While $30 \%$ agreed that 4-8 hours of pre-clinical experience to be beneficial, $70 \%$ agreed that greater than 8 hours would be more beneficial. $100 \%$ of the students recommended the pre-clinical experience for the didactic portion of a front loaded nurse anesthesia program (see Table 4).

Table 1. Survey questions responses (\%)

\begin{tabular}{|c|c|c|c|c|c|c|}
\hline ITEM & Question & SA & $\mathbf{A}$ & $\mathbf{N}$ & $\mathbf{D}$ & SD \\
\hline 1 & The PCE was overall beneficial to my education. & 96 & & & & 4 \\
\hline 2 & The PCE helped to reinforce the didactic curriculum. & 100 & & & & \\
\hline 3 & The PCE increased my confidence towards the clinical year. & 79 & 21 & & & \\
\hline 4 & The PCE helped to reduce anxiety towards the clinical year. & 71 & 25 & & 4 & \\
\hline 5 & The PCE increased my time spent reviewing didactic content. & 58 & 26 & 8 & 4 & 4 \\
\hline 6 & The PCE encouraged me to want to learn the theory behind what I experienced. & 92 & 4 & 4 & & \\
\hline 7 & I spent more time in lab practicing skills prior to attending pre-clinical rotations. & 42 & 42 & 12 & 4 & \\
\hline 8 & I spent more time in lab practicing skills after attending pre-clinical rotations. & 50 & 42 & 8 & & \\
\hline 9 & The PCE motivated me to study. & 92 & 4 & 4 & & \\
\hline 10 & The PCE created an understanding of the impact of anesthesia and surgery on patient's lives. & 96 & 4 & & & \\
\hline 11 & The PCE promoted professional association. & 71 & 17 & 8 & 4 & \\
\hline 12 & The PCE promoted the integration of prior knowledge and new knowledge. & 100 & & & & \\
\hline
\end{tabular}

Note. PCE: Pre-Clinical Experience; SA: strongly agree; A: Agree; N: Neutral; D: Disagree; SD: Strongly Disagree.

Table 2. Survey questions responses (\%)

\begin{tabular}{|c|c|c|c|c|c|c|}
\hline ITEM & Question & VH & $\mathbf{H}$ & SH & NH & NR \\
\hline 13 & Describe the PCE in improving your understanding of future responsibilities of a CRNA. & 92 & 8 & & & \\
\hline 14 & Describe the PCE in improving your professional development as a CRNA. & 83 & 17 & & & \\
\hline
\end{tabular}

Note. CRNA: Certified Registered Nurse Anesthetist; VH: very helpful; H: helpful; SH: somewhat helpful; NH: not helpful; NR: no response. 
Table 3. Survey questions responses (\%)

\begin{tabular}{|c|c|c|c|c|}
\hline ITEM & Question & $\mathbf{Y}$ & $\mathbf{N}$ & NR \\
\hline 15 & During the PCE, were you able to get hands-on practice with airway management? & 92 & 8 & \\
\hline 16 & During the PCE, were you able to get hands-on practice with gas machine check? & 39 & 61 & \\
\hline 17 & During the PCE, were you able to get hands-on practice with pre-operative evaluation? & 54 & 38 & 8 \\
\hline 21 & Would you recommend the PCE for the didactic portion of a front-loaded CRNA program? & 100 & & \\
\hline
\end{tabular}

Note. CRNA: Certified Registered Nurse Anesthetist; PCE: pre-clinical experience; Y: yes; N: no; NR: no response.

Table 4. Survey questions responses (\%)

\begin{tabular}{|c|c|}
\hline ITEM & Question \\
\hline 19 & $\begin{array}{l}\text { Describe the difference between shadowing a nurse anesthetist before starting the nurse anesthesia program and the } \\
\text { hands-on pre-clinical experience. }\end{array}$ \\
\hline \multicolumn{2}{|c|}{ I understand what was going on and why they were doing a thing in a deeper and theoretical manner. } \\
\hline \multicolumn{2}{|r|}{$\begin{array}{l}\text { Night and day difference. So much more made sense and was relevant to me, where shadowing was not as informative as I once } \\
\text { thought. }\end{array}$} \\
\hline \multicolumn{2}{|r|}{ Huge difference. I was able to use what I learned in class and understood SO MUCH more and the theory behind it. } \\
\hline Hands & re-clinical experience put everything together that I have been learning in class. Before, I had no real cl \\
\hline
\end{tabular}

\section{Discussion}

The current study findings supported that pre-clinical experience alleviates student stress in a traditionally front loaded academic program (see Tables 1-6). By providing students with 4 hours of clinical experience in the didactic portion of the 27-month course of study, the program assisted in reliev- ing perceived anxiety and improved confidence for students transitioning to clinical education. This effort aligns with previous studies completed in other medical specialties. ${ }^{[1-6]}$ The curricular modification helped to reinforce the didactic curriculum and fostered motivation to learn and study the theory linked to the student's clinical experience.

Table 5. Shadowing a nurse anesthetist versus pre-clinical experience (\%)

\begin{tabular}{|c|c|c|c|c|c|c|}
\hline ITEM & Question & $0-2$ & 4-8 & 8-12 & $>12$ & NR \\
\hline 20 & How many hours in the PCE do you consider most beneficial? & & 29 & 38 & 33 & \\
\hline
\end{tabular}

Table 6. Pre-clinical experience-hands-on practice

\begin{tabular}{l} 
ITEM Question \\
\hline $18 \quad$ Please describe any other hands-on practice you had during your pre-clinical experience. \\
Attempted intubation. I was unsuccessful, and this made me go back to the lab and practice the portions of the procedure I felt \\
uncomfortable with. Additionally, I spoke with some of the professors on how to improve my technique. This was a great learning \\
experience. \\
Had the opportunity to intubate a patient. \\
I was able to develop an anesthetic plan for a patient based on the case and the patient, then implement the induction portion of the \\
plan. It involved picking drugs and dose and giving induction medications followed by placement of an LMA. Establishing the plan \\
and having someone critique and give pointers on things to change or improve upon was very beneficial, especially in a real life \\
situation where I can bring that experience back to the lab and practice some more. \\
Patient positioning Pre-op lab evaluation Pre-op antibiotics administration Induction and muscle relaxation meds administration \\
Awakening of the patient, extubation. Patient transfer to PACU.
\end{tabular}

This survey was the first attempt at assessing the students' perception of early clinical experience as it relates to academic performance, confidence and anxiety in a nurse anesthesia program. To add, the nurse anesthesia educational

literature is devoid of information on this significant perspective. The students spent more time in the anesthesia simulation laboratory after attending the pre-clinical rotation to further perfect skills exposed to in the clinical arena, 
although the amount was not quantified. A testament to motivating student learning was offered by one student: "Attempted intubation. I was unsuccessful, and this made me go back to the lab and practice the portions of the procedure I felt uncomfortable with. Additionally, I spoke with some of the professors about how to improve my technique. This was a great learning experience" (see Table 6). This phenomenon had not been reported in previous studies. The experience promoted the integration of prior knowledge and new knowledge and created an understanding of the impact of anesthesia and surgery on patients' lives. Furthermore, it improved the students understanding of future responsibilities as a nurse anesthetist and was helpful in improving their professional development. ${ }^{[7]}$ The hands-on practice with specific skills smoothed the students transition into the clinical rotations (see Tables 1-3).

"Hands on pre-clinical experience put everything together that I have been learning in class. Before, I had no real clue what I was looking at. It all came together during the pre- clinical experience" (see Table 5). This comment from a nurse anesthesia student underscored the purpose of the study. The findings in this study established a clear benefit of providing the students with a pre-clinical experience. Previous research demonstrated that a reduction in anxiety and an increase in confidence will smooth the transition to clinical education ${ }^{[10]}$ which prompted the current study. Research shows that pre-clinical experience improves preparation for clinical rotations by immersing students in a real clinical environment, by facilitating the application of knowledge to clinical practice, and by improving students' motivation for learning. ${ }^{[8]}$

The results of this research underscore the benefits of early clinical experience. The results of this experience substantiate the positive influence pre-clinical experience made on the nurse anesthesia students. The literature consistently shows a benefit to early integration into the clinical arena. ${ }^{[1-12]}$ The current study demonstrated the same perceived benefits when including pre-clinical experience in a front-loaded nurse anesthesia program.

\section{Limitations}

Limitations exist in that this project examined one small cohort of nurse anesthesia students in one university. The study needs to be replicated, perhaps with multiple programs to generate greater evidence for perceived and actual benefits of preclinical experience in front-loaded clinical programs. The students may have felt the need to respond positively to the pre-clinical experience to present a positive impression to the faculty. Reliability and validity of the survey tool require attention to be able to generalize the findings to a larger population. For this reason, the current study results are not generalizable. Rather, this is an initial effort, a descriptive study that explores a new arena for the benefits of pre-clinical experience in a front-loaded nurse anesthesia program. A larger study following the determination of the survey's reliability and validity is in order.

\section{Conclusion}

The current study provides a foundation for continued research regarding the benefits of preclinical education including confidence and anxiety levels. Specifically, future research needs to examine a correlation between pre-clinical experience and test performance as well as overall performance in the students' first clinical rotation. Future research may inform curricular innovation for nurse anesthesia education and possibly, for graduate programs in other professional clinical disciplines.

\section{CONFlicts OF INTEREST Disclosure}

The authors declare that there is no conflict of interest.

\section{REFERENCES}

[1] Syed IAS, Mukhtar A. Medical students' anxiety on beginning clinical studies. Medical Education. 2013; 6(3): 195-201.

[2] Bell K, Boshuizen H, Scherpbier A, et al. When only the real thing will do: junior medical students' learning from real patients. Medical Education. 2009; 43(11): 1036-1043. PMid:19874495 http://dx.doi.org/10.1111/j.1365-2923.2009.03508.x

[3] Widyandana D, Majoor G, Scherpbier A. Preclinical students' experiences in early clerkships after skills training partly offered in primary health care centers: a qualitative study from Indonesia. BMC Medical Education. 2012; 12: 35. PMid:22640419 http: //dx.doi.org/10.1186/1472-6920-12-35

[4] Jackson MB, Keen M, Wenrich MD, et al. Impact of a pre-clinical clinical skills curriculum on student performance in third-year clerkships. J of General Internal Medicine. 2009; 24(8): 929-33. PMid:19521738 http://dx.doi.org/10.1007/s11606-009-1 $032-7$

[5] Littlewood S, Ypinazar V, Margolis SA, et al. Early practical experience and the social responsiveness of clinical education: systematic review. BMJ: British Medical Journal. 2005; 331(7513): 387-3914.

[6] Dornan T, Bundy C. What can experience add to early medical education? Consensus survey. British Medical Journal. 2004; 329: 834-837. PMid:15472265 http://dx.doi.org/10.1136/bmj . 329.7470 . 834

[7] Turner S, White J, Poth C, et al. Learning the roles in a near-peer shadowing program: a mixed methods randomized control trial. Med- 
ical Teacher. 2012; 34(11): 888-892. http://dx.doi.org/10.31 09/0142159x.2012.716179

[8] Watt E, Murphy M, Pascoe E, et al. An evaluation of a structured learning programme as a component of the clinical practicum in final year bachelor of nursing programme: a pre-post-test analysis. Journal of Clinical Nursing. 2011; 20(15/16): 2286-2293. PMid:21453297 http://dx.doi.org/10.1111/j.1365-2702.2010.03621.x

[9] Helmich E, Bolhuis S, Laan R, et al. Early clinical experience: do students learn what we expect?. Medical Education. 2011; 45(7): 731-740. http://dx.doi.org/10.1111/j.1365-2923. $2011.03932 . x$
[10] Hulse J, Chenowith T, Lebedovych L, et al. Predictors of student success in the US Army Graduate Program In Anesthesia Nursing. AANA Journal. 2007; 75(5): 339-346. PMid:17966677

[11] Carroll-Perez I. A study comparing characteristics of nurse anesthesia programs with the success rate on the certification examination. AANA Journal. 1996; 64(1): 76-80. PMid:8928605

[12] Godefrooij MB, Diemers AD, Scherpbier AJ. Students' perceptions about the transition to the clinical phase of a medical curriculum with preclinical patient contacts; a focus group study. BMC Med Educ. 2010; 10: 28. PMid:20367885 http://dx.doi.org/10.1186/1 $472-6920-10-28$ 